\title{
Knowledge Regarding Neonatal Jaundice Management among Mothers: A Descriptive Study Done In a Tertiary Level Hospital of Dhaka City
}

\author{
*S Huq ${ }^{1}$, SM Hossain ${ }^{2}$, SMT Haque ${ }^{3}$, MA Tarafder ${ }^{4}$
}

\begin{abstract}
Background: Jaundice is the most common clinical condition in the newborn that requires medical attention. This study was carried out in order to assess the knowledge on neonatal jaundice management among the mothers in a selected tertiary level hospital of Dhaka city.

Methodology: It was a descriptive type of cross-sectional study. 150 samples were selected by non randomized purposive sampling technique with the administration of a pretested, modified and semistructured questionnaire by face to face interview.

Results: Study found that majority of the respondents (76.7\%) was in the age group 17-27 years with mean age $23.78 \pm 5.397$ years. Majority of the respondents $(83.3 \%)$ had heard about neonatal jaundice previously and $16.7 \%$ did not hear about it. Regarding Knowledge on preventive measures of NNJ (neonatal jaundice) 90.6\% respondents had knowledge on "Putting jaundiced baby under direct sun light", $62.7 \%$ said "Herbal remedies", $48 \%$ indicated "Consult with doctor" and 12\% had knowledge on "phototherapy". Another major finding from the study was that $7.3 \%$ respondents had excellent level of knowledge regarding NNJ, whereas $40.0 \%, 34.0 \%$ and $18.7 \%$ had satisfactory, good and poor level of knowledge respectively. The Chi-square test model showed a significant association between previous knowledge of the respondents on NNJ with level of knowledge among the respondents $(p=0.027)$ and age of the respondents $(\mathrm{p}=0.012)$.
\end{abstract}

Conclusion: Awareness should be created among the expecting mothers about neonatal jaundice and encourage them to take preventive measures to avert neonatal mortality and morbidity.

Key Words: NNJ (Neonatal Jaundice), Knowledge, Mother

\section{Introduction}

Neonatal jaundice (NNJ) is still a leading cause of preventable brain damage, physical and mental handicap, and early death among infants in many communities. Greater awareness is needed among all health care workers ${ }^{1}$. Neonatal morbidity and mortality remain very high in the developing countries of sub-Saharan Africa, Asia and Latin
America $^{2}$, and one of the important contributors to this is neonatal jaundice ${ }^{3,4}$.

Jaundice due to unconjugated hyperbilirubinemia is also the most common clinical problem in the neonatal period in many parts of the world ${ }^{5}$. NNJ causes brain damage (kernicterus) when severe ${ }^{6}$, leading to neurological handicap and early death of affected infants.

${ }^{1}$ Dr. Sazia Huq, Senior Lecturer \& Coordinator, Department of Public Health, Northern University Bangladesh

${ }^{2}$ Prof. Dr. (Lt Col) Sarder Mahmud Hossain, Professor and Head, Department of Public Health, Northern

University Bangladesh

${ }^{3}$ Dr. Syed Mohammad Tanjilul Haque, Assistant Professor, Department of Forensic Medicine, Anwer Khan Modern Medical College \& Hospital

${ }^{4}$ Prof. Dr. Monowar Ahmed Tarafder, Head, dept of Community Medicine, ZH Sikder Women's Medical College

*Corresponding Author

Date of submission: 25.03.2017, Date of acceptance: 08.05.2017 
Jaundice is a common, often temporary and relatively harmless development in newborn babies, but sometimes it can be a sign of a more serious problem ${ }^{7}$. The neonatal period is the first 28 days of life, when the neonate is at maximum risk $^{8}$. Neonatal morbidity and mortality is still high in African, Asian, Latin American, and, developing countries of which one of the most important contributing factors is jaundice. It presents in $60 \%$ of term neonates and $80 \%$ of preterm ${ }^{9}$. The maximum risk of hyperbilirubinemia is Kernicterus because of accumulation of unconjugated bilirubin in serum. According to a study, Kernicterus causes at least $10 \%$ of mortality and $70 \%$ of morbidity. However, correct use of phototherapy and blood exchange to control serum bilirubin level, can prevent complications ${ }^{10}$.

Neonatal jaundice (NNJ) is a major public health problem worldwide and is present among $50-60 \%$ of full term and $80 \%$ of preterm newborns, neonatal jaundice accounted for $13.5 \%$ of all admissions, placing it third on the list of causes requiring admissions for neonates ${ }^{11,12}$. Neonatal jaundice is recognized as a major problem in other Asian countries as well ${ }^{13}$. However, large-scale prospective studies documenting incidence of jaundice have not been reported from any part of the world ${ }^{14}$.

\section{Materials and Methods}

This was a descriptive type of cross sectioned study.

All mothers who attended in a tertiary level hospital in Dhaka city, Bangladesh were the target population and the sample population was all the mothers' who were present at the time of data collection in the selected hospital in Dhaka city, Bangladesh. The study was carried out at Dhaka Medical College Hospital, Dhaka from October 2015 to January 2016 with a sample size of 150 and non randomized purposive sampling method was applied.

Data was collected by pretested and modified, selfadministered semi-structured questionnaire by face to face interview. All the post natal mothers who gave consent was included in the study and those who refused to give consent and was found to be mentally handicapped were excluded from the study.

All questionnaires were checked for its completeness and correctness. Coding and classification were done. The analysis was carried out with the help of SPSS (Statistical package for social science) Windows software program version 19. Descriptive statistics was used for the interpretation of the findings. Cross tabulation and association was determined by use of chi-square test. Filled questionnaires were checked daily for completeness and consistency of the responses to eliminate possible errors.

\section{Ethical consideration}

* Permission from Ethical Review Committee of Northern University of Bangladesh and from study place.

* Written Informed consent obtained prior to the interview.

* Confidentiality of the respondents was maintained.

* Respondents' had rights to refuse and withdraw from the study at any time.

\section{Limitations of the study}

The followings were the limitation of the study:

- Time was very limited.

- Limitation of the fund.

- Small study area could not represent the whole.

\section{Results}

The following Variables of table no 1 describes Socio demographic characteristics of the study population. They are as following: age, religion, education, marital status, occupation, income, types of family \& number of family member of the respondents etc. Majority of the respondents (76.7\%) were in the age group 17-27 years and $23.3 \%$ was in 28-40 years of age group with mean age 23.78 \pm 5.397 years. Most of the respondents (93.3\%) were Muslim, and $64 \%$ of the respondents completed primary level of education. Majority of the respondents (92.7\%) were house wife and $44 \%$ 
of the respondents' monthly family income was BDT 5001-10000.

Majority of the respondents correctly answered the knowledge related questions like, Is Jaundice in newborn is yellowish discoloration of skin (92\%). Another knowledge related questions which were correctly answered by the respondents, Is Jaundice is a common problem of newborns (74\%), Is it abnormal if jaundice lasting for more than 2 weeks (76.7\%). Majority of the respondents replied correctly when they had been asked that, Is NNJ is a cause of improper breastfeeding (80\%), Is premature delivery is a risk factor of NNJ (72\%), Does jaundice lasts for 2 weeks in case of preterm babies $(63.3 \%)$, Is any infection of newborns can be a risk factor for NNJ (60\%), Foods taken by mothers can cause jaundice in infants (46\%), Severe jaundice may cause death in neonates $(75.3 \%)$, Is blood testing by medical personnel needed to detect jaundice in infants $(84.7 \%)$. (table 2 )

Table 1: Distribution of the respondents by sociodemographic variables

\begin{tabular}{|c|c|c|c|}
\hline & Socio-demographic Variables & Frequency & Percentage \\
\hline \multirow{3}{*}{$\stackrel{\Delta}{\not}$} & $17-27$ & 115 & 76.7 \\
\hline & $28-40$ & 35 & 23.3 \\
\hline & Total & 150 & 100.0 \\
\hline \multicolumn{4}{|c|}{ Mean age $=23.78 \pm 5.397$} \\
\hline \multirow{4}{*}{ 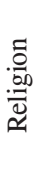 } & Islam & 140 & 93.3 \\
\hline & Hinduism & 8 & 5.3 \\
\hline & Christianity & 2 & 1.3 \\
\hline & Total & 150 & 100.0 \\
\hline \multirow{6}{*}{ 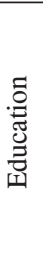 } & Illiterate & 10 & 6.7 \\
\hline & Primary & 95 & 63.3 \\
\hline & Secondary & 29 & 19.3 \\
\hline & Higher secondary & 11 & 7.3 \\
\hline & Graduation and above & 5 & 3.3 \\
\hline & Total & 150 & 100.0 \\
\hline \multirow{3}{*}{ 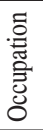 } & House wife & 139 & 92.7 \\
\hline & Govt. service & 11 & 7.3 \\
\hline & Total & 150 & 100.0 \\
\hline \multirow{6}{*}{ 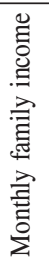 } & $\mathrm{BDT}<5000$ & 39 & 26.0 \\
\hline & $5001-10000$ & 66 & 44.0 \\
\hline & $10001-15000$ & 7 & 4.7 \\
\hline & $15001-20000$ & 28 & 18.7 \\
\hline & $\mathrm{BDT}>25000$ & 10 & 6.7 \\
\hline & Total & 150 & 100.0 \\
\hline
\end{tabular}

Table 2: Distribution of respondents by knowledge on NNJ $(n=150)$

\begin{tabular}{|c|c|c|}
\hline Knowledge on NNJ & Answers & Percentage $(\%)$ \\
\hline \multirow{2}{*}{$\begin{array}{l}\text { Is Jaundice in newborn is } \\
\text { yellowish discoloration of skin }\end{array}$} & True* & 92 \\
\hline & Don't know & 8 \\
\hline \multirow{3}{*}{$\begin{array}{l}\text { Is Jaundice is a common } \\
\text { problem of newborns }\end{array}$} & True & 74 \\
\hline & False & 0.7 \\
\hline & Don't know & 25.3 \\
\hline \multirow{2}{*}{$\begin{array}{l}\text { Is it abnormal if jaundice } \\
\text { lasting for more than } 2 \text { weeks }\end{array}$} & True & 76.7 \\
\hline & Don't know & 23.3 \\
\hline \multirow{2}{*}{$\begin{array}{l}\text { Is NNJ is a cause of improper } \\
\text { breastfeeding }\end{array}$} & True & 80 \\
\hline & Don't know & 20 \\
\hline \multirow{2}{*}{$\begin{array}{l}\text { Is premature delivery is a risk } \\
\text { factor of } \mathrm{NNJ}\end{array}$} & True & 72 \\
\hline & Don't know & 28 \\
\hline \multirow{2}{*}{$\begin{array}{l}\text { A treatment of NNJ is } \\
\text { phototherapy }\end{array}$} & True & 45.3 \\
\hline & Don't know & 54.7 \\
\hline \multirow{3}{*}{$\begin{array}{l}\text { Does jaundice lasts for } 2 \text { weeks } \\
\text { in case of preterm babies }\end{array}$} & True & 63.3 \\
\hline & False & 2.7 \\
\hline & Don't know & 34 \\
\hline \multirow{3}{*}{$\begin{array}{l}\text { Is any infection of newborns } \\
\text { can be a risk factor for NNJ }\end{array}$} & True & 60 \\
\hline & False & 1.3 \\
\hline & Don't know & 38.7 \\
\hline \multirow{3}{*}{$\begin{array}{l}\text { Foods taken by mothers can } \\
\text { cause jaundice in infants }\end{array}$} & True & 46.0 \\
\hline & False & 26.7 \\
\hline & Don't know & 27.3 \\
\hline \multirow{3}{*}{$\begin{array}{l}\text { Maternal drugs such as } \\
\text { sulphonamides or anti-malarial } \\
\text { can cause pathological jaundice } \\
\text { in new borne }\end{array}$} & True & 17.3 \\
\hline & False & 28 \\
\hline & Don't know & 54.7 \\
\hline \multirow{3}{*}{$\begin{array}{l}\text { Severe jaundice may cause } \\
\text { death in neonates }\end{array}$} & True & 75.3 \\
\hline & False & 2 \\
\hline & Don't know & 22.7 \\
\hline \multirow{2}{*}{$\begin{array}{l}\text { Is blood testing by medical } \\
\text { personnel needed to detect } \\
\text { jaundice in infants }\end{array}$} & True & 84.7 \\
\hline & Don't know & 15.3 \\
\hline
\end{tabular}

Table no 2 reveals that majority of the respondents answered the true answer regarding knowledge related question on NNJ.

Table 3: Distribution of respondents by knowledge on preventive measures of $\mathrm{NNJ}(\mathrm{n}=150)$

\begin{tabular}{lcc}
\hline $\begin{array}{l}\text { Knowledge on preventive } \\
\text { measures of NNJ }\end{array}$ & Frequency (n) & Percent (\%) \\
\hline $\begin{array}{l}\text { Putting jaundiced baby under } \\
\text { direct sun light }\end{array}$ & 135 & $90.6 \%$ \\
Herbal remedies & 94 & $62.7 \%$ \\
Phototherapy & 18 & $12 \%$ \\
Consult with doctor & 72 & $48 \%$ \\
\hline
\end{tabular}

* Multiple responses 
Regarding Knowledge on preventive measures of $\mathrm{NNJ}$, it was found from table no 3 that among the respondents $90.6 \%$ had knowledge on "Putting jaundiced baby under direct sun light", $62.7 \%$ said "Herbal remedies", 48\% indicated "Consult with doctor" and $12 \%$ had knowledge on "phototherapy".

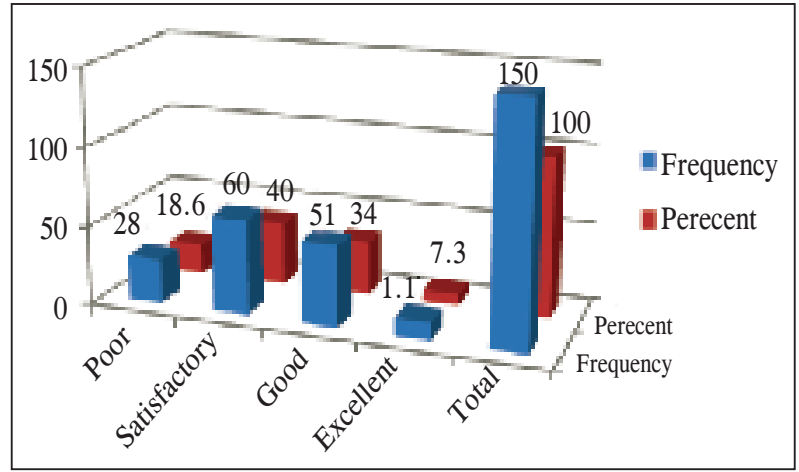

Figure 1: Distribution of the respondents by levels of knowledge

Among the respondents $40 \%$ had satisfactory knowledge, $34 \%$ had good knowledge, $18.6 \%$ had poor knowledge and only $7.3 \%$ had excellent knowledge regarding neonatal jaundice.

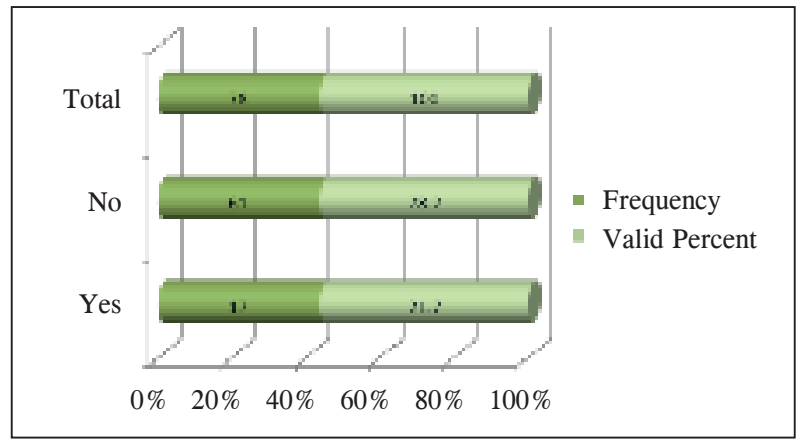

Figure 2: Distribution of the respondents by history of jaundice in previous issues of pregnancy $(n=78)$

Another important finding was that among those who were reported as multipara $78.2 \%$ of the respondents' neonate was not affected by jaundice whereas $21.7 \%$ replied positively to this.
Table 4: Distribution of the respondents by association between age and knowledge on management of $\mathrm{NNJ}$

\begin{tabular}{lccccc}
\hline \multirow{2}{*}{$\begin{array}{l}\text { Age in } \\
\text { years }\end{array}$} & \multicolumn{5}{c}{ Knowledge on management of NNJ } \\
\cline { 2 - 6 } & $\begin{array}{c}\text { Sun } \\
\text { lighting } \\
\text { the baby }\end{array}$ & $\begin{array}{c}\text { Herbal } \\
\text { remedies }\end{array}$ & Phototherapy & $\begin{array}{c}\text { Consult } \\
\text { with } \\
\text { doctor }\end{array}$ & Total \\
\hline $17-27$ & 104 & 72 & 15 & 61 & 252 \\
$28-40$ & 31 & 22 & 03 & 11 & 67 \\
Total & 135 & 94 & 18 & 72 & 319 \\
p-value & 0.748 & 0.979 & 0.476 & 0.025 & \\
\hline
\end{tabular}

It is found from table no 4 that 17-27 years old respondents had good level of knowledge regarding management of NNJ rather than 28-40 years of respondents. Association was found only in between age of the respondents and knowledge on management of $\mathrm{NNJ}$, which was consultation with doctors. $(p=0.025)$

Table 5: Distribution of the respondents by association between previous knowledge on NNJ and level of knowledge

\begin{tabular}{|c|c|c|c|c|c|c|}
\hline \multirow{2}{*}{$\begin{array}{c}\text { Previous } \\
\text { knowledge } \\
\text { on NNJ }\end{array}$} & \multicolumn{4}{|c|}{ Level of knowledge } & \multirow{2}{*}{ Total } & \multirow{2}{*}{ p-value } \\
\hline & Poor & Satisfactory & Good & Excellent & & \\
\hline Yes & 18 & 53 & 44 & 10 & 125 & 0.027 \\
\hline No & 10 & 7 & 7 & 1 & 25 & \\
\hline Total & 28 & 60 & 51 & 11 & 150 & \\
\hline
\end{tabular}

Among the respondents who had previous knowledge on NNJ scored higher while they were asked about knowledge related question.

\section{Discussion}

A cross sectional study was conducted to assess the knowledge on neonatal jaundice management among the 150 post-natal mothers attending a selected tertiary level hospital in Dhaka city, Bangladesh from September 2015 to December 2015. Data was analyzed by using statistical packages for social science (SPSS) software version 19.0. A semi structured questionnaire, consisting 31 questions divided into two parts was used to collect the information. Section-A contained the question about the socio-demographic characteristics of the respondents, Section-B contained question about knowledge of the respondents regarding neonatal 
jaundice management. The data presented in the form of table and graph. Chi-square is used to calculate the association between demographic variable and knowledge of the respondents.

Observing socio demographic characteristics of the respondents, it was found that majority of the respondents $(76.7 \%)$ was in the age group 17-27 years and $23.3 \%$ was in $28-40$ years of age group with mean age $23.78 \pm 5.397$ years. Almost similar finding was revealed in a study conducted in Malaysia by Boo et al where the mean age was $26.8 \pm 6.5$ years $^{15}$.

Study also showed that most of the respondents (93.3\%) was Muslim followed by Hindu (5.3\%) and only $1.3 \%$ were Christian. More than half $(64 \%)$ of the respondents completed their primary education followed by secondary level of education (19\%) and higher secondary level and graduation $7 \%$ and 3\% respectively. It is revealed that only $7 \%$ were illiterate. Among all $44 \%$ of the respondents monthly family income was BDT 5001-10000, followed by $26 \%, 18.7 \%, 6.7 \%$ and $4.7 \%$ respondents had a monthly family income BDT $<5000$, BDT 15001-20000, BDT >25000 and BDT 10001-15000 respectively. Occupation wise majority of the respondents $(92.7 \%)$ was house wife and $7.3 \%$ was Govt. service holder. A quite different finding was noticed in a study conducted in Nigeria by Ogunlesi TA and Abdul AR where most of the mothers had tertiary level of knowledge. This educational variation among mothers has been observed as Bangladeshi women are still neglected and scope of their education is still very poor.

Majority of the respondents $(86.0 \%)$ reported that their previous baby was not affected with jaundice but $14.0 \%$ replied positively. The finding is exactly similar with the study conducted by Egube in Nigeria. The study showed that $14.1 \%$ of respondents had previous experience with $\mathrm{NNJ}^{17}$.

Majority of the respondents correctly answered the knowledge related questions like, Is Jaundice in newborn is yellowish discoloration of skin (92\%). A quite dissimilar finding was observed in a study conducted by Egube BA at Nigeria that only $51.5 \%$ of the respondents gave a correct definition of $\mathrm{NNJ}^{17}$. This difference is likely due to difference in socio-demographic criteria of two countries. Another knowledge related questions which were correctly answered by the respondents, Is Jaundice is a common problem of newborns (74\%), Is it abnormal if jaundice lasting for more than 2 weeks (76.7\%), in relation to this quite similar finding was found in a study done by Boo NY, et al in Malaysia where it was seen that $71.7 \%$ knew that jaundice lasting more than 2 weeks was abnormal ${ }^{15}$.

Majority of the respondents replied correctly when they had been asked that, Is NNJ is a cause of improper breastfeeding (80\%), Is premature delivery is a risk factor of NNJ (72\%), Does jaundice lasts for 2 weeks in case of preterm babies (63.3\%), Is any infection of newborns can be a risk factor for NNJ (60\%), Foods taken by mothers can cause jaundice in infants $(46 \%)$, Severe jaundice may cause death in neonates $(75.3 \%)$, Is blood testing by medical personnel needed to detect jaundice in infants (84.7\%). Almost consistent finding has been found in a study conducted by Boo $\mathrm{NY}$ et $\mathrm{al}^{15}$ regarding severe jaundice may cause death in neonates', where it has been seen that $71.7 \%$ of the mothers knew that severe jaundice could cause death in newborn.

Current study also found that only $45.3 \%$ of the respondents knew about phototherapy as treatment of NNJ. Almost similar finding was observed in a study conducted by Ogunfowora $\mathrm{OB}$ et al in Nigeria ${ }^{18}$, where it was found that $54.5 \%$ had adequate knowledge on effective treatment namely phototherapy and exchange blood transfusion.

Regarding Knowledge on preventive measures of NNJ it was found that among the respondents 90.6\% had knowledge on "Putting jaundiced baby under direct sun light", $62.7 \%$ said "Herbal remedies", $48 \%$ indicated "Consult with doctor" and $12 \%$ had knowledge on "phototherapy".

These findings completely vary from the study done in Nigeria by Boo $\mathrm{NY}^{15}$ possibly due to difference in knowledge pattern of the respondents of two different countries.

Another major finding was that $7.3 \%$ respondents had excellent level of knowledge regarding NNJ, whereas satisfactory level of knowledge by $40.0 \%$, 
good by $34.0 \%$ and poor level of knowledge by $18.7 \%$. These findings are consistent with a study findings conducted by Ogunlesi TA et al in Nigeria, in which it was reported that out of 98 mothers, $57.1 \%$ had good knowledge on newborn jaundice ${ }^{16}$.

Strong association was found between age of the respondents and previous knowledge of the respondents about NNJ $(p=0.012)$. There was also an association between previous knowledge of the respondents on NNJ and level of knowledge among the respondents $(\mathrm{p}=0.027)$.

It was also seen from the study that those who were more younger (17-27 yrs) in age are more knowledgeable than those of who were older (28-40 yrs), A significant association was also found between age and "consultation with doctor" $(\mathrm{p}=0.025)$.

\section{Conclusion}

It can be concluded that mothers of Bangladesh are yet to be aware regarding NNJ as only $7.3 \%$ of the respondents were found to have excellent knowledge regarding NNJ. Neonatal care has always been neglected in our country as yet Bangladeshi people are not properly educated. More over cultural values and customs make rural women out of focus regarding $\mathrm{ANC}$ and neonatal care. As women can not ask for their Reproductive right, mortality and morbidity are still high among rural mothers. It is the policy makers who can take necessary measures to make the rural mothers aware and save thousands of neonates and mothers.

\section{Recommendation}

As per the findings of the study, following recommendations are suggested:

- Awareness program should be conducted among the mothers attending gynecological inpatient and out-patient department.

- Further study also can be conducted to have greater view regarding the knowledge on neonatal jaundice care among mothers with larger sample size covering the whole Bangladesh.
Conflict of interest: none.

\section{References}

1. Olusoga B, Ogunfowora, Olusoji J Daniel. Neonatal jaundice and its management: knowledge, attitude and practice of community health workers in Nigeria. BMC Public Health 2006; 6:19

2. Zupan J. Perinatal mortality in developing countries. New Eng/ J Med 2005; 352:20472048. Available from: URL:

http://www.nejm.org/doi/full/10.1056/NEJM p058032

3. Owa JA, Oshinaike AI. Neonatal morbidity and mortality in Nigeria. Indian J Pediatr 1998; 65:441-449

4. Parkash J, Das N. Pattern of admissions to neonatal unit. J Coll Physians Surg Pak 2005; $15: 341-344$.

5. Escobar GJ, Greene JG, Hulac P, Kincannon E, Bischoff $\mathrm{K}$, et al. Re-hospitalization after birth hospitalization: patterns among infants of all gestations. Arch Dis Child 2005; 90:125-131.

6. Hansen TW: Treatment of neonatal jaundice. Tidsskr Nor Laegeforen 2005; 125:594-598. Available from: URL:

http://www.ncbi.nlm.nih.gov/pmc/articles/PM C1409785/

7. Ali SM. Knowledge and Practices of Nurses Working in Neonatal Intensive Care Units toward Neonatal jaundice Kirkuk and Erbil Cities. Zanco J. Med. Sci., (special issue 2): 2010.

8. Andreoli T, Carfenter C. Cecil Essentials of Medicine. 5th ed. Philadelphia: W.B. Saunders, 2001, pp 371-2.

9. Behrman R, Kliegman R, Jenson H, eds. Nelson Text book of Pediatrics. 17th ed. Philadelphia: Saunders, 2004: 523-599. 
10. IP S, Chang M, Kulig J, O'Brian R, Sege S, Glicken et al. An evidence-based review of important issues concerning neonatal hyperbilirubinemia. Pediatrics 2004: 114.

11. AA Roberts, AFR Alabede, FA Olatona. Neonatal Jaundice: A Survey of Perinatal Correlates among Mothers of Infants Attending Immunization Clinic in Surulere Local Government Area. Journal Home. 2014; 66:1-2.

12. Parkash J \& Das N (2005) Pattern of admission to neonatal unit. Journal of the College of physicians and surgeons- Pakistan 15:341-344.

13. Ho NK (1992) Neonatal jaundice in Asia. Baillieres Clinical Haematology 5:131-142. Available from: URL:

http://onlinelibrary.wiley.com/doi/10.1111/j.1 365-3156.2010.02496.x/full

14. Anonymous (2004) Management of hyperbilirubinemia in the newborn infant 35 or more weeks of gestation. Pediatrics 114: 297316.
15. Boo NY, Gan CY, Gian YW, Lim KSL, Lim MW, Kumar HK. Malaysian Mothers' Knowledge and practices on care of Neonatal Jaundice. Med J Malaysia. August 2011; 66 (3).

16. Ogunlesi TA, Abdul AR. Maternal knowledge and care-seeking behaviors for newborn jaundice in Sagamu, Southwest Nigeria.Niger J ClinPract. 2015 Jan-Feb; 18(1):33-40.

17. Egube BA, Ofili AN, Isara AR, Onakewhor JU. Neonatal jaundice and its management: Knowledge, attitude, and practice among expectant mothers attending antenatal clinic at University of Benin Teaching Hospital, Benin City, Nigeria. Nigerian Journal of Clinical Practice. Apr-Jun 2013; 16(2).

18. Ogunfowora OB, Daniel OJ. Neonatal jaundice and its management: knowledge, attitude and practice of community health workers in Nigeria. BMC Public Health. 2006 Jan 27; 6: 19 